\title{
Para pensar comunicação, cultura e subjetividade: uma perspectiva de análise $e^{a}$ To think about communication, culture and subjectivity: an analytical perspective
}

\author{
MÁRCIO SOUZA GONÇA LVES b \\ Universidade do Estado do Rio de Janeiro, Programa de Pós-Graduação em Comunicação. Rio de Janeiro - \\ RJ, Brasil
}

\section{RESUMO}

O presente texto procura fazer uma síntese da perspectiva que defendemos para a análise das relações entre comunicação, cultura e subjetividade. Trata-se, nos três âmbitos, de evitar o que nomeamos de paradigma epocalista, em favor de abordagens localizadas e atentas às diferenças. Nossa perspectiva envolve, em primeiro lugar, evitar uma visão classificatória das subjetividades. Além disso, evita-se a redução da história das culturas a uma sucessão linear de épocas. Finalmente, evita-se, do mesmo modo, tanto o determinismo tecnológico quanto a ideia de um usuário onipotente, o que implica considerar tanto as agências das tecnologias quanto as ações dos usuários tomados individual ou coletivamente.

Palavras-chave: Comunicação, cultura, subjetividade, epocalismo, tempo

\section{ABSTRACT}

This article summarizes the perspective we favor for the analysis of the relationships between communication, culture and subjectivity. In all three domains, it is about avoiding what we call the epochalist paradigm, in favor of localized approaches attentive to differences. Our perspective involves, first of all, avoiding a classificatory view of subjectivities. In addition, reduction of cultural history to a linear succession of epochs is avoided. Finally, both technological determinism and the idea of an omnipotent user are avoided as well, which implies considering both technology agencies and user actions, on an individual or collective basis.

Keywords: Communication, culture, subjectivity, epochalism, time 


\section{INTRODUÇÃO}

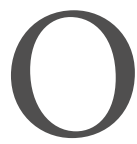

DURO PERÍODO QUE atravessou nos últimos anos, e ainda atravessa, a universidade a que estamos vinculados, a Universidade do Estado do Rio de Janeiro (Uerj), que envolveu sobretudo o não pagamento de salários e bolsas de pesquisa, com atrasos acumulados de vários meses, nos levou a colocar, intimamente, uma série de questões sobre o que é pesquisar e ensinar em um país como o Brasil e sobre o significado de se desenvolver atividades intelectuais em um universo com tamanhos problemas estruturais. Perguntamo-nos, assim, em última instância, pelo sentido do que fazemos cotidianamente em nosso trabalho universitário, tanto solitária quanto coletivamente, e se vale a pena tal investimento. Essas questões, de ordem estritamente pessoal, nos conduziram, de modo mais ou menos involuntário, à realização de um balanço do que consideramos realmente importante em nossa trajetória intelectual. Parte de tal balanço se materializa no presente texto, onde procuramos delinear e agrupar alguns elementos que avaliamos como contribuições nossas que podem ser de interesse para o campo das pesquisas em comunicação no Brasil. Este artigo, desse modo, se tem origem no universo pessoal de questões sobre nossa trajetória existencial, desemboca em algo que, pretendemos, possa talvez ser de interesse mais amplo.

Nossas pesquisas sempre se apoiaram, pelo menos desde o doutorado, em um tripé composto pelos elementos subjetividade, cultura e tecnologia de comunicação.

Por subjetividade entendemos a dimensão humana, mental, psicológica, mas que envolve também o corporal, se se considera que não existe humano sem corpo, que toda mente é mente incorporada. O conceito freudiano de pulsão, elemento que se situa na fronteira entre o somático e o psíquico, permite que se pense bem essa dupla presença ou articulação da subjetividade humana. O subjetivo, além disso, embora tenha uma dimensão individual, é, para além e para aquém do indivíduo, infra e suprapessoal. Pensemos, por exemplo, por um lado, nas máquinas desejantes, elementos moleculares de constituição do inconsciente, de que falaram Deleuze e Guattari (1976) e, por outro, na complexa antropologia filosófica de Simondon (2007).

Cultura tomamos em um sentido bastante amplo, de modo a englobar todo o universo existencial humano presente e passado, seus valores, produções, aspectos materiais e imateriais, tudo o que constitui o contexto humano de existência. Trata-se, assim, de uma definição muito vaga e propositadamente aberta e inclusiva.

As tecnologias de comunicação, do mesmo modo, são por nós tratadas com bastante generosidade e abertura, não sendo restritas ao universo das 
mídias elétricas. Obviamente, tudo o que faz parte do universo do eletrônico e do digital é aqui visto como tecnologia de comunicação, mas aí incluímos também o impresso, o manuscrito, a escrita, o imagético, até mesmo em suas dimensões pré-históricas, e, no limite, a própria fala. A lista do que pode ser incluído nessa definição generosa de tecnologia de comunicação seria extensa demais para ser tentada aqui, de modo que nos abstemos de tal iniciativa, mas não sem indicar que, dependendo das condições de produção e uso, praticamente qualquer coisa pode ser encarada e operada, circunstancialmente, repetimos, como tecnologia de comunicação.

No tripé que sempre orientou nossas investigações, se articulam, portanto, a dimensão humana tanto individual quanto coletiva, o contexto de existência dos seres humanos e as tecnologias de comunicação, tomadas em um sentido bastante amplo.

\section{SUBJETIVIDADE}

Uma teorização classificatória da subjetividade parece ter sucedido a versão kantiana de um sujeito transcendental e a psicanalítica de um sujeito descentrado. Trata-se, então, não mais de pensar um sujeito que valha para o humano, seja o kantiano, seja o excentrado freudiano, mas de recortar tipos de subjetividade distintos.

Tal teoria classificatória, em sua versão mais comum, opõe um sujeito dito moderno a um sujeito pós-moderno. A terminologia pode variar, mas o esquema opositivo é o mesmo: humano e ciborgue, identidade centrada e identidade híbrida, identidade e identificação, homem tipográfico e homem eletrônico, humano e pós-humano. Essas são algumas das formas que essa classificação pôde tomar em diferentes momentos e constelações teóricas.

O esquema opera, em primeiro lugar, com dois tipos de subjetividade, identidade, sujeito ou mente, pouco importando para nossa discussão, repetimos, qual dos termos é invocado. Eventualmente os dois tipos podem dar lugar a três, sendo o terceiro uma recuperação do primeiro, portanto em um esquema ternário que de algum modo resolve o binário (esquema que não seria exagerado nomear como dialético).

A oposição entre os tipos é clara, um sendo como que o negativo do outro. Assim, por exemplo, o sujeito moderno é racional, centrado, oposto a tudo o que não é humano, consciente, alienado, na medida em que a emoção perde para a razão etc. O pós-moderno é excêntrico, definido por processos mais afetivos do que racionais, híbrido, misturado, extrapola em muito a consciência, recupera uma forma de unidade entre razão, afeto etc. Como dito, o esquema pode operar com três termos, o que coloca então uma forma de sujeito pré-moderno, 
definido como holista, coletivo, emocional, oral, entre outros epítetos, em marcada oposição ao moderno. Pré-moderno, moderno e pós-moderno designariam assim três formações subjetivas diferentes, com a nuance de que o sujeito pós-moderno recupera e atualiza, como dissemos, em larga escala, traços do sujeito pré-moderno.

Note-se, de passagem, que em geral o sujeito pré-moderno é valorizado como uma espécie de ideal primevo de unidade cuja integridade é rompida pelo sujeito moderno especializado e alienado, o sujeito pós-moderno operando então uma forma de redenção da fragmentação da modernidade em direção a uma nova integração. Contemplamo-nos, finalmente, em nossa organicidade:

No presente, o mecânico começa a ceder terreno à unidade orgânica, por força das condições das velocidades elétricas. $\mathrm{O}$ homem pode agora olhar para trás e contemplar dois ou três mil anos de mecanização em vários graus, consciente de que o mecânico não foi senão um interlúdio entre dois grandes períodos orgânicos da cultura. (McLuhan, 2005, p. 176)

A classificação dos tipos de sujeito é também execução de um juízo de valor sobre esses sujeitos, que são vistos positiva ou negativamente em função das preferências e paradigmas teóricos utilizados como base. Conforme se julgue de um modo ou de outro, nosso tempo é então visto como um tempo de redenção, subjetiva mas também cultural, de um modo por vezes messiânico, ou de grande decadência. McLuhan (2005) e Innis (2007), autores estranhamente agrupados sob o termo frankensteiniano de escola de Toronto, manifestam respectivamente essas duas posições.

Classificação e julgamento, portanto, em primeiro lugar. Mas, além disso, essas formações subjetivas são ordenadas em uma ordem que é ao mesmo tempo lógica e cronológica.

Ordenação lógica: a unidade primeva é rompida para ser posteriormente recuperada, de modo que se tem inicialmente o sujeito pré-moderno, ao qual sucedem o moderno e finalmente o pós-moderno. Unidade-fragmentaçãounidade fecha o círculo da subjetividade em um encadeamento que não poderia se fazer em outra ordem.

Ordenação cronológica: a humanidade teria, temporalmente, dado origem, em primeiro, lugar a sujeitos pré-modernos. As culturas orais, holísticas, primitivas, mítico-religiosas e outras qualificações do mesmo gênero vieram no início produzindo seu tipo humano. Em algum momento da nossa história, que é situado por alguns ao longo do segundo milênio da era cristã, com a invenção da prensa, as grandes navegações, o Renascimento, a Reforma etc., mas que outros situam bem 
antes no tempo, quando da invenção da escrita e sobretudo da escrita alfabética, o sujeito pré-moderno holista deu lugar à fragmentação racional visual do sujeito moderno, perdendo-se assim a unidade em favor de uma hipertrofia, na maior parte das vezes vista como danosa, de uma das faculdades humanas. Esse sujeito visual teria vigorado, se é que tal termo faz sentido, até recentemente, quando então entramos em uma outra fase subjetiva, com o surgimento de uma nova forma de sujeito, que exorciza, é o caso de se dizer, a separação característica do sujeito moderno. Haveria, portanto, uma sucessão cronológica das formas subjetivas: primeiro fomos pré-modernos, depois modernos, finalmente pós-modernos. Lógica e cronológica se acordam totalmente.

Até agora temos três termos importantes na estruturação desse paradigma de compreensão da subjetividade humana: classificação, julgamento e ordenação. Cabe acrescentar um quarto ponto: o operador das passagens.

Para a discussão que nos interessa aqui, o operador da passagem de um tipo de sujeito para outro é, em geral, uma tecnologia de comunicação, o que equivale a dizer que cada formação subjetiva é definida por uma ou um grupo de tecnologias de comunicação.

O sujeito pré-moderno, holista e selvagem, seria definido pela comunicação oral, pela tecnologia da fala. As culturas orais engendrariam, assim, os sujeitos pré-modernos. A passagem para o sujeito moderno em geral é atribuída a duas tecnologias diferentes, tomadas isoladamente ou em conjunto: a escrita alfabética e/ou a prensa tipográfica. A escrita alfabética teria determinado o aparecimento de uma consciência filosófica, da separação entre sujeito e objeto e, portanto, de um modo de exercício da razão que comumente é ligado tanto à filosofia quanto à ciência. À prensa tipográfica é atribuído o mesmo efeito, o que não deixa de ser curioso, e o surgimento da forma moderna das ciências é então invocado como prova do caráter revolucionário da prensa. A passagem para a pós-modernidade subjetiva remete, seja às tecnologias eletrônicas, seja às digitais. Estaríamos, no século que é o nosso, na aurora, tanto comunicativa quando subjetiva, de uma nova era.

As tecnologias de comunicação operariam, então, independentemente de o paradigma teórico ser mais otimista ou mais pessimista, uma revolução subjetiva e levariam ao surgimento de novos sujeitos.

Temos assim, em suma, uma classificação de tipos de sujeitos, uma valorização positiva ou negativa dos diversos tipos, uma ordenação lógica e cronológica e, finalmente, uma definição dos operadores de passagem de um tipo de formação subjetiva para outro. Trata-se, agora, de problematizar criticamente todo esse conjunto de elementos envolvido nessa forma de compreender e teorizar a questão da subjetividade e do sujeito. 
Comecemos pelo problema da classificação. O que exatamente é referido quando se fala em sujeito pré-moderno, moderno, pós-moderno? Uma resposta direta: tais termos se referem não a sujeitos concretos encarnados em corpos concretos, indivíduos reais com sua existência histórica, mas sim a idealizações que se distanciam bastante da realidade.

Algo como um bom selvagem naturalmente em harmonia consigo e com seu grupo se encontra na base da ideia de subjetividade pré-moderna. Ora, tal equilíbrio, unidade ou integração efetivamente existe ou existiu? Lembremos apenas a colocação de Descola (2006) acerca do individualismo nas culturas ditas primitivas:

A filosofia política, com efeito, vulgarizou num esboço rudimentar uma oposição entre, de um lado, as sociedades surgidas na Europa ocidental da união do capitalismo com a ideologia das Luzes - onde o indivíduo, fonte de direitos e proprietário de sua pessoa, é a pedra de toque sobre a qual se assenta o edifício coletivo - e, de outro, as sociedades pré-modernas, totalidades estruturadas por hierarquias imutáveis, nas quais o indivíduo está ausente ou, pelo menos, só tem sentido e existência enquanto elemento de um conjunto que o define por inteiro. Ora, se as sociedades fundadas na preeminência do todo sobre as partes de fato cobriram boa parte da face da terra antes do triunfo dos parlamentos, em contrapartida existem outras, não menos numerosas, mas decerto muito menos conhecidas, que colocaram na realização de um destino individual livremente dominado e aberto a todos o mais alto valor de sua filosofia social. Os Achuar são desse tipo: pouco preocupados em conceber a si mesmos enquanto comunidade orgânica, esquecidos do próprio passado e indiferentes ao futuro, submetendo o idioma do parentesco às exigências de seus interesses imediatos, preocupados com o seu prestígio pessoal e prontos para desertar os que gostariam de envolver demais os outros em sua própria glória, só são freados na exaltação de si mesmos pela falta, no seu meio, de uma plateia para aplaudi-los. (pp. 333-334)

A ideia de um sujeito holista, se pode ser aplicada em alguns casos, dificilmente dá conta da complexidade total da organização subjetiva nas sociedades orais, primitivas, selvagens ou outro termo que se queira. Veja-se, em outro contexto, o caso de Montaillou, tratado por Le Roy Ladurie (1997), que dificilmente pode ser caracterizado como um caso de subjetividade moderna, devendo ser, portanto, pré-moderno: tais sujeitos, lógica e cronologicamente pré-modernos, têm de lidar com uma gama enorme de questões, contradições, heterogeneidades e cada pessoa daquela comunidade resolve a seu modo essa plêiade de elementos estruturando uma forma singular de existência subjetiva. 
Ou seja, tudo ocorre, no mundo real, de um modo diferente do que nos faz crer o conceito de subjetividade pré-moderna.

O mesmo pode ser dito para o suposto sujeito moderno: uma pesquisa antropológica, histórica ou de psicologia histórica não vai encontrar, dentro do que se chama de período Moderno, ou no Contemporâneo, ou no Renascimento, se se quiser recuar a modernidade no tempo, nada desse ser racional, estruturado, centrado etc. Claro que sempre há indivíduos mais ou menos racionais e equilibrados, mas há também os completamente fora do eixo, e nada permite definir o modo mental de existir das pessoas dentro desses momentos históricos como pautados pela razão em maior ou menor grau do que hoje. Pensemos nas condições de existência subjetiva nas fábricas inglesas durante a Revolução Industrial, nas derivas mais emocionais dos grupos humanos na Revolução Francesa etc. Germinal, de Zola (1979), é talvez a grande crônica dessa inadequação da ideia de subjetividade moderna, na medida em que revela, ao mesmo tempo, o ideal epocal burguês e a total inadequação das pessoas e da realidade a tal projeto: as diversas oposições que estruturam o livro - entre burgueses e mineiros, entre os próprios mineiros, entre a superfície solar e as negras profundezas das minas -, a mistura absoluta de corpos e mentes, especialmente entre os trabalhadores, a irracionalidade e a violência constante, tudo isso mostra quanto a realidade se distancia dos ideais teóricos de uma razão vitoriosa. O que aí germina é sobretudo uma fina ironia para com a visão idílica epocalista da modernidade triunfante. São exemplos de subjetividades engajadas em vidas que têm muito pouco da clareza e estabilidade centrada e racional que a ideia de sujeito moderno sugere.

A chave para se compreender essa ideia de sujeito moderno, quimera confortável que permite que nos definamos como melhores ou piores do que nossos antepassados, está não no mundo da vida, mas no pensamento de certos filósofos - no entanto deixaremos esse assunto para logo a seguir. A mesma complexidade subjetiva que temos nos momentos que antecedem o nosso encontramos no nosso: há pessoas as mais variadas, mais ou menos racionais, mais ou menos centradas em discursos os mais variados, mais ou menos em boa convivência com seus semelhantes e grupos de pertencimento. Não se encontra nada que permita definir uma diferença essencial entre os humanos que viveram em épocas anteriores e nós mesmos. Claro que diferenças existem, mas do mesmo modo como existem profundas diferenças convivendo simultaneamente em qualquer momento da história. Hoje, como em séculos passados, há variadas formas de existência subjetiva, heterogeneidades coexistindo em maior ou menor conflito.

Assim, em vez de situar uma diferença fundamental entre sujeitos de diferentes épocas, como se todos os sujeitos de uma época fossem o mesmo, 
preferimos situar as diferenças no interior de todos os contextos históricos: há sempre variedade subjetiva convivendo, claro que em maior ou menor grau, dependendo do grupo humano, seu tamanho e uma série variada de fatores, mas sempre variedade subjetiva. Nunca uma pasteurização homogênea dos sujeitos como a classificação que estamos criticando faz supor.

Nossa posição é a de que a subjetividade é sempre, em qualquer momento, a produção de certa coerência, relativa e instável, a partir de um conjunto enorme de elementos, que são econômicos, sociais, corporais, religiosos, familiares, educacionais, idiossincráticos etc. Toda pessoa (na falta de termos melhores, pessoa pode ser uma boa escolha) agencia em sua existência esses conjuntos múltiplos para existir mental e socialmente. Não há propósito, assim, em se falar em uma classificação ou tipologia de sujeitos: todos os sujeitos são iguais, no sentido de serem esses agenciamentos singulares de heterogeneidades. No universo da subjetividade, a regra é que não há regra. Criar tipos seria reduzir a infinita variedade da vida a termos genéricos tão vazios quanto imprecisos.

Uma hipótese que nos parece correta, mas que não nos interessa explorar aqui, é a de que toda essa classificação de tipos de sujeito repousa em uma confusão envolvendo a filosofia. O sujeito (no caso o moderno) enquanto conceito filosófico, categoria central da filosofia de Descartes ou de Kant - em que desempenha um papel epistemológico importante, coadunando-se perfeitamente com a crença filosófica em uma onipotência da razão - terminou sendo tomado pelos proponentes dessas teorias classificatórias como um ente existente empiricamente, como a descrição de pessoas em seus respectivos mundos da vida. $\mathrm{O}$ conceito filosófico de sujeito se tornou então a base idealizada para afirmação de que os primitivos, orais, não seriam assim e, no final das contas, nós mesmos, eletrônicos, não somos assim. Ora, nem os humanos da que a história chama de Era Moderna eram assim. Confunde-se o sujeito kantiano com a existência subjetiva do vizinho de Kant, como se o segundo vivesse como o primeiro; toma-se um conceito filosófico como descrição histórica das subjetividades, o que termina por produzir essas tipologias tão simplórias.

Há sentido em se fazer uma história do conceito de sujeito, subjetividade ou identidade e de seu surgimento e tratamento na filosofia. Mas é preciso que tal história se restrinja a seu campo próprio, ou seja, permaneça uma história do conceito em questão e não das pessoas concretas e seus modos de existir ao longo do tempo. O que é incorreto é tomar a história do conceito pela história das pessoas em seus mundos, da vida efetiva, em última instância. Assim, se há sentido em se falar em um conceito moderno de sujeito, não há sentido em comparar tal conceito às práticas subjetivas dos jovens em ambientes de games para sustentar que estes são diferentes daquele: o jovem atual no ambiente de 
games deve ser comparado com os jovens dos séculos anteriores em suas práticas de jogos, nunca com o sujeito transcendental kantiano. Tal truísmo não se revela um truísmo quando se percorre toda a discussão acerca das subjetividades pós-modernas, pós-humanas etc.

Esse modo de teorizar classificatório, assim, pode servir exclusivamente para pensar concepçães ou conceitos de sujeito, algo como antropologias filosóficas, ao longo da história da alta cultura ocidental. É, portanto, inadequado para dar conta dos sujeitos concretos em suas existências cotidianas.

Para evitar tais confusões, pode ser útil distinguir, a partir de qualquer terminologia que se considere adequada, o conceito de sujeito ou subjetividade ou identidade, tal como tratado em teorias da alta cultura, das práticas concretas de invenção de um si-mesmo, que podemos chamar de práticas de subjetivação, processos de subjetivação ou o que se considerar mais interessante, e que são, mais profundamente, as que todos os humanos exercitam ao longo de suas existências.

A crítica do sistema classificatório das subjetividades vai de par, obviamente, com a crítica da valorização deste ou daquele sujeito como melhor ou pior, mais ou menos verdadeiro, mais ou menos autêntico ou humano. Não há sentido em tais julgamentos de valor. Cada momento histórico, cada contexto humano, dá lugar a práticas de subjetivação próprias, que são as possíveis, dadas as condições locais. Portanto não se pode cometer a grosseria do anacronismo, julgando com critérios hodiernos outros contextos em outros momentos. Em resumo, não se pode dizer que os que viveram na pré-história, ou na suposta pós-história, são mais humanos ou estão mais próximos da verdadeira humanidade ou de uma humanidade mais integral, do que os homens da Idade Média, do Renascimento ou da década passada. Não há, deve estar claro, verdadeira humanidade, não há uma teleologia hegelo-mcluhaniana de um sujeito que no final se encontra cosmicamente consigo mesmo.

Do mesmo modo, e isso já foi tangenciado em alguns parágrafos anteriores, com a crítica da classificação produz-se, como corolário, a crítica da ordenação. Se se pode fazer a história cronológica e lógica dos conceitos de sujeito (e correlatos: subjetividade, identidade, identificação) e pensar, no âmbito dessa história dos grandes sistemas de pensamento da alta cultura - que não necessariamente é apenas filosófica, podendo ser também artística, religiosa etc. - em ordenamentos e dependências de tais conceitos em relação a tais outros, quando se olha para a vida concreta a situação se apresenta como bem mais resistente a esquematismos simples.

Como dissemos, especialmente quando introduzimos a crítica do suposto sujeito moderno (dez parágrafos em direção ao início deste texto), ao longo de toda a extensa história da presença humana sobre a Terra, encontramos pessoas 
diferentes umas das outras, engajadas em heterogêneas práticas de subjetivação. Ao invés de uma espécie de similitude global para os sujeitos de uma época, o que permitiria uma ordenação linear cronológica em relação a outras épocas, o que se tem são coexistências, sempre, de práticas de subjetivação distintas e variadas, eventualmente contraditórias, sempre singulares. À singularidade genética de cada pessoa se pode sobrepor uma singularidade subjetiva, dependente sempre de processos idiossincráticos de subjetivação. Em cada momento, em cada grupo cultural, cada pessoa agencia, a seu modo, os elementos diversos que a cultura, entendida no sentido largo, oferta, para construir, singularmente, uma forma de existência. Badiou (1995) resume bem "a evidente multiplicidade infinita da espécie humana, a qual é tão flagrante entre mim e meu primo de Lyon como entre a 'comunidade' xiita do Iraque e os gordos cowboys do Texas" (p. 40).

A crítica da ideia da passagem de uma forma subjetiva a outra por ação de um operador tecnológico de comunicação segue a mesma linha de argumentação e será feita mais adiante, quando tratarmos do terceiro elemento do tripé, que sempre definiu nossas pesquisas, exatamente as tecnologias de comunicação. Tal crítica, apenas para adiantar a discussão, passa pela desconstrução do determinismo tecnológico como maneira de se pensar a relação entre humanos e tecnologias.

\section{CULTURA}

Nossa eventual contribuição para uma reflexão sobre as relações entre cultura e os outros dois elementos do tripé passa, assim o acreditamos, pela proposição de um modo de pensar a mudança cultural e a estruturação dos contextos humanos que não caia na armadilha do que chamamos alhures de epocalismo (Gonçalves \& Clair, 2014).

Comecemos então por uma definição desse termo, que configura uma maneira grosseira e vaga de pensar os espaços culturais e da qual nos distanciamos fortemente. Relembramos aqui o que dissemos anteriormente: tomamos cultura de um modo bastante amplo, englobando tudo - material ou imaterial, corporal ou incorporal - que compõe os contextos em que os seres humanos existem.

Epocalismo é um modo de compreender a história das culturas humanas que pensa essa história e, portanto, a da própria humanidade, como uma sucessão linear de épocas. Cada época tem um caráter duplo, interno e externo. Por um lado, cada época é internamente homogênea: com isso se quer dizer que é idêntica, internamente, a si mesma, que seus componentes têm um grau tal de semelhança que justifica sua redução a um elemento comum definidor. Uma época se define, então, pela semelhança de todos os elementos que a compõem, 
o que designamos por semelhança ou homogeneidade internas. Assim, por exemplo, todos os elementos que compõem a época moderna seriam semelhantes entre si, o que justificaria seu agrupamento sob o termo moderno. Se houvesse uma parte significativa desses elementos que não fosse semelhante ao resto, a Modernidade ficaria como que rachada, uma época que teria em si uma outra época que não ela, uma Modernidade que teria em si uma não Modernidade, o que é uma ideia bastante interessante, mas que do ponto de vista do uso do termo é problemática pois solapa sua validade e seu sentido, uma vez que nesse caso a identidade da Modernidade seria não moderna: algo como falar em vermelho incluindo o verde como parte do vermelho, o que no limite embaralha toda a discussão sobre cores, pois quando se diz vermelho não se pode saber se se está falando de verde ou de vermelho ou de outra cor. Em suma, seguindo com o exemplo, não faz sentido falar em Modernidade se tal termo não recorta um conjunto coerente e homogêneo de elementos, se não segue o princípio da identidade, daí a necessidade da homogeneidade interna.

Por outro lado, externamente, o epocalismo assume que cada época é essencialmente diferente tanto da que a precede, se houver alguma, quando da que a sucede, se houver igualmente alguma. Seguindo esse pressuposto, haveria uma diferença essencial entre, por exemplo, a Modernidade e a Pós-Modernidade (ou Modernidade Tardia, ou Líquida, ou Contemporaneidade - como vimos, os temos utilizados são totalmente indiferentes se se mantém o paradigma epocalista; pode-se mesmo dizer que são intercambiáveis e não passam de detalhes semânticos). Essa diferença essencial seria o que tornaria possível a oposição ou separação entre ambas.

Assim como a semelhança interna é condição para que o nome de uma época tenha sentido, como vimos, a diferença para com as épocas vizinhas é necessária para que tanto a classificação das épocas quanto a avaliação e a ordenação sejam realizáveis. Se não há diferença externa e se, assim, por exemplo, a Modernidade é semelhante à Pós-Modernidade, não há sentido em nomeá-las com dois termos diferentes: mais profundamente, é o velho princípio dos indiscerníveis, de Leibniz, quem legifera: se dois elementos são indiscerníveis eles são o mesmo, ou seja, se não há diferença, Modernidade e Pós-Modernidade seriam a mesma coisa. Assim, deve haver necessariamente diferença entre duas épocas para que sejam consideradas duas épocas, diferença que aqui qualificamos de externa.

Em suma, e seguindo com nosso exemplo, se a Modernidade não é internamente homogênea e semelhante a si mesma, não tem sentido utilizar tal termo como categoria de análise; se a Modernidade não é diferente da PósModernidade, não há sentido em opô-las. As épocas têm, logo, semelhança interna e diferença externa. 
O epocalismo, assim, encara a história das culturas humanas como uma sucessão de épocas qualitativamente distintas, cada época sendo internamente homogênea e externamente diferente de outras épocas. Essas épocas se encadeariam em uma história linear, uma época sendo então substituída pela seguinte, que será substituída por outra e assim por diante. Um encadeamento de caixinhas, cada caixinha tendo um conteúdo homogêneo diferente dos conteúdos igualmente homogêneos das demais.

O esquema possivelmente mais comum do epocalismo, e isso foi mencionado quando falamos da subjetividade, é o esquema ternário que faz suceder, a uma época Pré-Moderna (ou tribal, primitiva, oral, selvagem etc.), uma época Moderna, à qual sucede uma época Pós-Moderna (ou Modernidade Tardia, Modernidade Líquida, Contemporaneidade etc.). Mas, assim como para os tipos de subjetividade, pode-se encontrar um esquema binário que opõe vagamente Modernidade e Pós-Modernidade: nesse caso o Pré-Moderno permanece implícito como condição negativa para a emergência do Moderno. As datações são frequentemente bem vagas quando se trata de caracterizar mais precisamente tais termos e não parece haver um consenso ou regra geral sobre o tema, a não ser o fato de que se coadunam mal com as clássicas definições da história de período antigo, medieval, moderno e contemporâneo.

Já mencionamos, mas devemos destacar enfaticamente que a terminologia utilizada para se referir às diferentes épocas em sua sequência linear é indiferente se se mantém a crença básica de que a história das culturas humanas se faz pela sucessão de blocos homogêneos diferentes uns dos outros, cada um com seus traços básicos próprios, ou se se pensa a história como uma sucessão encadeada de gavetinhas bem arrumadas, para usar uma metáfora doméstica. Tanto faz se se nomeia a gaveta anterior à nossa de $\mathrm{X}$ ou $\mathrm{Y}$ quando se trabalha com a ideia de que gavetas são adequadas, como ferramentas conceituais, para pensar realidades tão complexas como conjuntos culturais.

O problema geral do epocalismo é pensar semelhança e diferença de uma maneira grosseira e genérica. Claro é, em primeiro lugar, que semelhança e diferença dependem da escala de análise utilizada, sendo, portanto, relativas. Dada uma situação qualquer, pode-se pensar semelhanças ou diferenças entre elementos relativamente a um parâmetro qualquer: o parâmetro cor coloca um carro preto perto de um gato preto, enquanto o parâmetro matéria-prima certamente os coloca como essencialmente diferentes. Não há, desse modo, semelhança ou diferença absoluta.

Ora, para tomar toda a infinidade diferencial dos elementos que compõem um contexto histórico de alguns séculos, infinidade diferencial tanto de elementos incorporais como materiais, e etiquetar essa miríade sob um termo 
único, é preciso escolher deixar de lado um número muito grande de variações e heterogeneidades e tomar como parâmetro de análise algum traço bastante geral que, mesmo em sua genericidade, é sempre insuficiente.

Se se considera um parâmetro bastante geral, tal como a presença ou ausência de escrita, por exemplo, é possível dividir as culturas em orais e escritas, assumindo o pressuposto de que as culturas orais são semelhantes entre si e de que as culturas escritas são semelhantes entre si, de que não há nas culturas orais traços que remetam ao que se agrupa sob a escrita e vice-versa, de que há, além disso, uma clara diferenciação entre ambas. Toma-se assim a escrita como parâmetro e pressupõe-se a homogeneidade interna de todas as culturas orais de um lado e escritas de outro, e, em segundo lugar, a diferença externa entre esses dois conjuntos amplos.

Tais pressupostos são bastante problemáticos: para tomar um exemplo interessante, a racionalidade, atribuída pelas teorias de cunho epocalista ao surgimento da escrita, está claramente presente nas culturas orais: veja-se, por exemplo o pensamento selvagem (Lévi-Strauss, 2010) ou as estruturas burocráticas dos grandes impérios antigos anteriores à escrita (Schmandt-Besserat, 2006). Há, assim, traços importantes que deveriam ser exclusivos das culturas escritas dentro das orais; há igualmente, por outro lado, traços orais fortes dentro das culturas letradas: tanto o pressuposto da homogeneidade interna quanto o da diferença externa se revelam insuficientes... O caso do Brasil é especialmente instrutivo, pois vivemos em um país que parece desafiar qualquer etiqueta ou classificação simplória, sendo ao mesmo tempo oral, escrito, eletrônico, digital, moderno, pós-moderno, pré-moderno, o que torna ainda mais curiosa a aceitação de teorias epocalistas por pesquisadores brasileiros.

O preço da adoção das etiquetas epocalistas gerais é produzir uma descrição teórica tão ampla que fique obrigada a desconsiderar uma série enorme de elementos locais que não se encaixam dentro do que a teoria descreve como realidade, produzindo assim uma forma de cegueira para os detalhes concretos da realidade, que é deletéria quando se reflete sobre determinadas questões.

Situamo-nos, portanto, bastante criticamente em relação a tal tipo de teorização. O problema essencial que o epocalismo tenta resolver, de modo canhestro a nosso ver, é o da mudança na história e no tempo: agora vamos procurar esboçar, assim, um modo alternativo de reflexão que pense a diferença no tempo sem recorrer a ideias gerais de épocas internamente homogêneas e externamente opostas.

De modo direto, a primeira tese de nossa proposição pode ser enunciada assim: cada contexto humano se compõe de um conjunto sempre heterogêneo de elementos, por vezes até contraditórios, mas que mesmo assim de algum 
modo se agenciam e fazem um conjunto que se mantém, sempre com ajustes, ao longo do tempo, e cuja consistência, sempre relativa, é a do próprio agrupamento humano. Assim, se se pega, ao acaso, o século XII europeu, destacamos, em uma lista que está muito longe de ser exaustiva, a religião cristã, uma cultura popular pagã cuja persistência medieval na Europa é bem estabelecida, a cultura oral, as universidades a partir de um certo momento, agricultura, nobreza, clero, cavaleiros, a tradição das iluminuras, a cultura manuscrita, guerras religiosas ou não, as características idiossincráticas de todos os que viveram naquele momento, as doenças, o amor cortês, o amor místico e, dentro de cada um desses itens, uma variação maior ou menor, uma vez que o cristianismo, por exemplo, pode ser vivido de modos bastante variados, e assim por diante. Há obviamente conflitos entre cristianismo e paganismo, entre grupos no caso das guerras, entre nobres e agricultores, mas igualmente dentro do cristianismo, dentro de um mesmo grupo social etc. Mas, de todo modo, no final das contas, tudo isso se agencia constituindo a vida humana na Europa do século XII. Primeira diferença em relação ao epocalismo: longe de apresentar uma homogeneidade interna que lhe permita ser reduzido a um traço único dominante, todo contexto é múltiplo, heterogêneo, contraditório, qualquer dominação sendo, portanto, bastante relativa e local, nunca global. Todo contexto é composto de múltiplos estratos heterogêneos que coexistem (o exemplo de Montaillou, anteriormente citado, é paradigmático).

Segunda tese: a passagem do tempo acarreta, em maior ou menor grau, reorganizações ou rearranjos entre os elementos ou estratos heterogêneos. Tais rearranjos podem se dar, mas nem sempre, a partir da introdução de elementos ou estratos novos. Assim, por exemplo, o Renascimento, como movimento cultural, engendra alterações em diversos campos conexos: religioso, artístico, antropológico etc. Não se trata do desaparecimento da religião em favor do humanismo, mas de uma composição entre os termos; do desaparecimento de toda a arte pré-renascentista, que obviamente permanece e ainda retornará posteriormente; ou do desaparecimento de uma entidade absoluta intitulada homem medieval em favor de um novo homem igualmente abstrato, o do Renascimento. Cada ser humano continua fazendo o que sempre fez, produzindo uma ressonância entre elementos culturais variados, presentes e passados, para construir para si uma identidade sempre provisória: a diferença é que há novos elementos ou estratos na composição, sem que isso implique o abandono dos velhos.

Terceira tese: os rearranjos podem ser mais ou menos fortes, mais ou menos traumáticos, o que usualmente é pensado sob o par de termos revolução e evolução. No fundo, é o mesmo tipo de processo, em maior ou menor grau, com maior ou menor velocidade. 
A mudança histórica, assim, envolve sempre, fundamentalmente, continuidade, mas coexistindo com processos de ruptura locais que levam, eventualmente, a reestruturações maiores nas relações entre os diversos estratos presentes. A descontinuidade, quando presente, se faz sobre continuidades mais profundas e obviamente afeta a elas e seu desenvolvimento. Mais do que opostos, continuidade e descontinuidade são processos complementares que se condicionam reciprocamente. A ideia de uma absoluta descontinuidade entre épocas, na medida em que despreza as permanências, nos parece imprecisa.

Trata-se portanto de pensar a mudança histórica articulando permanências e rupturas, revoluções e evoluções, e operando com a ideia de que ocorre em diferentes velocidades sempre um rearranjo dos diversos elementos ou estratos que compõem qualquer contexto humano, seja com a presença de elementos ou estratos novos, seja simplesmente como reorganização dos antigos.

Esse deslocamento tem um correlato epistemológico: a redução do escopo de análise. Não há sentido e mesmo possibilidade de se cartografar essa existência dos diversos estratos e seus agenciamentos operando com contextos culturais amplos demais; é necessário, para que a teorização seja possível, o recorte de contextos mais localizados, o que permite que se analise em detalhe sua ordenação e seus estratos. Modernidade e Pós-Modernidade, por exemplo, fazem sentido dentro de uma abordagem epocalista. Dentro do paradigma que estamos sugerindo, trata-se antes de abordar comunidades menores com recortes temporais menores (podemos remeter novamente o leitor ao exemplo de Montaillou).

Às análises genéricas, gerais e globais, que operam com ferramentas amplas cujo recorte empírico é muito limitado, preferimos abordagens mais localizadas, menores, o que implica um trabalho com conceitos mais finos e delicados, cujo recorte empírico é mais produtivo.

Em suma, não se trata da sucessão de épocas internamente homogêneas e externamente diferenciadas, mas da coexistência de estratos ou elementos em agenciamentos precários em constante reorganização, seja ligada à presença de elementos novos, seja sem que nenhum estrato novo tenha sido acrescentado, havendo assim a simples reorganização do existente, que pode ser mais ou menos rápida.

\section{TECNOLOGIA DE COMUNICAÇÃO}

Como vimos, entendemos tecnologia em um sentido amplo, de modo que coisas que usualmente não são vistas como tecnologia caem sob a égide do termo. Assim, e estamos nos repetindo, sem mesmo tentarmos uma abordagem exaustiva, 


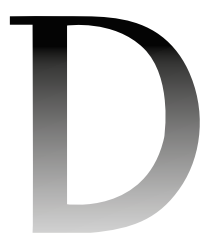

a fala, ela própria, pode ser encarada como uma tecnologia de comunicação, envolvendo um aparelho fonador (que os macacos, por exemplo, não têm) e uma aprendizagem, longa, de uso. Pessoas sem o aparelho fonador, que aliás precisa aprender a produzir os sons necessários para a fala de determinada língua, o substituem por outros aparelhos, as mãos, por exemplo, e devem então aprender formas de uso específicas. Um hipotético ser humano abandonado na natureza, e há vários casos reais de tais abandonos, não desenvolve o aparelho necessário nem aprende as capacidades indispensáveis para o uso da tecnologia fala e, portanto, não a usa. $\mathrm{O}$ mesmo argumento vale para a audição da fala humana.

A escrita, obviamente, é uma tecnologia: envolve o uso de aparatos (suporte, instrumento de inscrição), envolve uma aprendizagem muscular e cognitiva, tal como a fala, não é de modo algum um ato natural fisiológico. O mesmo vale para a leitura.

A música e os instrumentos musicais comunicam; a arquitetura comunica; rituais comunicam; assim como roupas, a poesia, a gestualidade corporal, a internet, a TV, o cinema, o rádio, o teatro etc.

Tomando assim tecnologia no sentido amplo, trata-se então de pensar sua relação com os outros dois elementos do tripé fundamental de nossas pesquisas, os humanos e as culturas.

A tese é simples: deve-se evitar o puro e tosco determinismo tecnológico, tanto individual quanto coletivo, ou ambos. Portanto é necessário que se pense as agências dos meios conjugadas com os usuários e grupos de usuários, $\mathrm{o}$ contexto cultural em que operam, as tradições de utilização e assim por diante. Ou seja, pensar os efeitos dos meios não a partir puramente deles próprios, mas em relação aos usos a que são submetidos.

Por determinismo tecnológico entende-se, aqui, a ideia de que os meios por si mesmos engendram efeitos necessários simplesmente em função de sua presença em um ambiente cultural dado habitado por seres humanos. Tais efeitos, em geral, estão ligados mais à forma das tecnologias de comunicação do que ao tipo de mensagem que veiculam, o que se resume bem na tese de que os meios são as mensagens. McLuhan é paradigmático quanto a esse modo de pensar: a tecnologia oral causa em termos individuais um equilíbrio dos sentidos, engendrando um espaço acústico; as tecnologias da escrita alfabética e da prensa tipográfica produzem uma hipertrofia da visão e a substituição do espaço acústico pelo espaço visual, com todas as consequências sociais e individuais que isso acarreta; os meios eletrônicos, finalmente, nos libertam da tirania do olho e produzem um retorno tanto a um equilíbrio dos sentidos quanto ao espaço acústico perdido (trata-se, considerando o que indicamos, de um epocalismo ternário) (McLuhan \& McLuhan, 2007). 
Deve-se, sustentamos, evitar tais perspectivas que desconsideram os contextos e os usos e atribuem um poder divino aos meios, esquecendo-se de que são produtos humanos originados em ambientes culturais específicos. Quanto a isso, não se pode, por exemplo, compreender a presença e a ação das prensas tipográficas na cultura europeia dos séculos XV e posteriores sem levar em conta que a invenção atribuída a Gutemberg é o resultado de e responde a uma série de transformações bem anteriores que alteraram nossa relação com os textos manuscritos e produziram um grande aumento de demanda por material textual (cf. Barbier, 2006). Os meios se originam em contextos que os condicionam e sua agência se conjuga necessariamente com a agência humana.

A reflexão em torno dos usos e das apropriações humanas deve, contudo, superar algo que chamaremos de paradigma do usuário solitário, que consiste em considerar que o usuário individualmente seria dotado de uma espécie de livre arbítrio total e irrestrito no uso dos meios, de que o humano gozaria individualmente de uma liberdade absoluta e que poderia definir, conscientemente, a que uso e apropriação submeteria uma tecnologia qualquer, seja ela de comunicação ou não. Esse paradigma é uma espécie de herança iluminista na reflexão sobre a relação entre humanos e tecnologia, com a característica hipervalorização da individualidade e da racionalidade. Se se segue por esse caminho, a agência dos meios é reduzida a nada face à onipotência do usuário humano, de forma que caímos no exato simétrico do determinismo tecnológico. Entre o determinismo tecnológico e o paradigma do usuário solitário estamos assim em uma situação indecidível do tipo ou...ou, ou determinismo tecnológico ou onipotência do usuário solitário, em uma disjunção exclusiva. Ou os meios são onipotentes, ou os usuários são onipotentes. Trata-se antes, aqui o defendemos, de negar essas onipotências, de considerar que tanto uns quanto outros são agentes nos processos de uso e exercem efeitos, sendo necessário, portanto, sempre se considerar localmente, nos casos dados, e nunca abstratamente, em geral, que tipo de composição entre humanos e tecnologias tem lugar. Ou seja: deve-se sair da disjunção exclusiva.

Para superar o paradigma do usuário solitário, é importante considerar um terceiro elemento na relação entre indivíduo e máquina. Esse elemento é o grupo humano em que o uso se dá. As situações concretas de uso nunca comportam um indivíduo isolado do mundo, fechado em um cômodo com uma tecnologia, de comunicação ou não; o que sempre ocorre é o uso por alguém concretamente existente que pertence a grupos sociais que configuram certa forma de relação com a tecnologia em questão. Assim, o uso que um indivíduo faz da prensa é atravessado pelo grupo ou grupos a que esse indivíduo pertence: a Stationers' Company, por exemplo, tem um papel fundamental na determinação 
dos efeitos e usos das prensas na Inglaterra moderna (Johns, 1998). Em lugar do paradigma usuário individual/tecnologia, deve-se ter em mente uma tríade: usuário individual/grupos de pertencimento/ tecnologia. Isso complexifica a questão dos usos e torna presente o contexto sociocultural, na medida em que os próprios grupos de pertencimento são o contexto imediato de apropriação dos objetos tecnológicos.

Em suma, em lugar do determinismo tecnológico e do determinismo humano, formas simétricas que reduzem a complexidade da relação a um esquematismo simplório, devemos pensar na tríade usuário/grupos de usuários/ tecnologia, aceitando a complexidade singular das formas de agenciamento desses três termos.

\section{COMUNICAÇÃO, CULTURA E SUBJETIVIDADE}

Opusemos, em primeiro lugar, a uma visão classificatória da subjetividade, nossa ideia de práticas de subjetivação. Em vez de tipos de sujeitos, onipresentes processos de construção de uma certa coerência a partir de elementos heterogêneos, práticas constitutivas do humano. Produzimo-nos como sujeitos agenciando diversos elementos sociais, culturais, corporais e idiossincráticos, e isso desde sempre e em qualquer cultura. Mudam os elementos, claro, mas o processo de constituição de identidades sempre precárias é constante.

Opusemos, em segundo lugar, a uma visão epocalista da cultura, a concepção de que qualquer contexto cultural é um agregado de elementos ou estratos heterogêneos, e mesmo conflitantes ou contraditórios. A história das culturas humanas não é, portanto, vista como a da substituição de um tipo de cultura idêntico a si mesmo e distinto dos outros tipos por um novo e assim sucessivamente; os contextos culturais se misturam, estratos são acrescentados, mas outros permanecem, de modo que não se trata nunca da substituição de um tipo ideal por outro, mas sempre do rearranjo constante de estratos. Revolução e evolução não são vistas, então, como contraditórias, mas como faces do mesmo processo, na medida em que a revolução em um estrato se enxerta sobre a evolução em outros e assim sucessivamente.

Opusemos, finalmente, ao determinismo tecnológico e ao determinismo humano, um modo de pensar a relação entre usuários e tecnologias como composição entre, de um lado, o que os meios permitem fazer e, de outro, os usos que se fazem, por indivíduos, mas sobretudo por grupos humanos, que dão sentido ao agir individual. Substituímos a lógica binária de usuário ou máquina como determinante, portanto, por uma lógica ternária, em que temos o usuário individual, os grupos de pertencimento e as tecnologias, operando em agenciamentos sempre singulares e contextuais. 
Duas observações se impõem. Em primeiro lugar, os três deslocamentos que operamos implicam que devam ser abandonadas as macroanálises, tanto no que tange ao problema da subjetividade, quanto da cultura, das tecnologias de comunicação e da relação dos três campos. Em lugar de falar genérica e globalmente sobre os sujeitos de uma época definidos (ou intocados) pelas tecnologias com as quais se comunicam, é preciso realizar análises locais sobre como determinados indivíduos ou grupos se constituem subjetivamente em contextos históricos específicos, agenciando-se mais ou menos de modo idiossincrático com tecnologias de comunicação etc. Metodologicamente, nesse sentido, o campo da comunicação tem muito a ganhar com uma aproximação com alguns campos conexos afeitos a um tratamento localizado e específico de contextos culturais bem delimitados. Assim, por exemplo, podemos pensar no campo da antropologia e na etnografia, no campo da história e nas diversas técnicas de micro-história etc. (Burke, 1992; Campanella \& Barros, 2016; Chartier, 2002; Geertz, 1983; Peirano, 1995; Revel, 1998).

Em segundo lugar, deve ser mais ou menos evidente para um leitor atento que a visão classificatória da subjetividade e da cultura bem como o determinismo tecnológico estão intimamente relacionados, de tal modo que uma correlação parece se estabelecer: um dos termos termina por levar aos outros dois. São, em última instância, três formas de epocalismo, com a homogeneidade interna e a diferença externa que indicamos: a subjetiva, um tipo de sujeito é substituído na história por outro; a cultural, uma época por outra; a tecnológica, um meio hegemônico por outro, com o poder de definir o conjunto do socius.

Abandonar a visão classificatória dos sujeitos, das culturas e dos meios de comunicação implica, mais profundamente, abandonar esse paradigma de um epocalismo generalizado em favor de um pensamento mais delicado, localizado e atento às diferenças. A mudança da escala de análise, com o abandono das grandes etiquetas epocalistas, deve nos aproximar mais de uma realidade concreta tanto mais fascinante quanto mais irredutível à linearidade das categorias gerais. Se se quiser uma regra geral, mas fora do estilo epocalista das etiquetas globais genéricas, tal regra poderia se enunciar: há sempre diferença em agenciamento, subjetivo, cultural, tecnológico. Trata-se, assim, de uma regra geral vazia, que indica a necessidade do abandono das discussões genéricas e amplas em favor dos casos existentes. O aprofundamento da compreensão implica a redução da ambição da compreensão: em lugar de tratar genericamente o todo, melhor tratar delicadamente os pedaços.

Esperamos, timidamente, que aqui tenha se desenhado uma possível contribuição para o pensamento das questões da comunicação. $\mathbf{M}$ 


\section{REFERÊNCIAS}

Badiou, A. (1995). Ética: Um ensaio sobre a consciência do mal. Rio de Janeiro, RJ: Relume-Dumará.

Barbier, F. (2006). L'Europe de Gutenberg: Le livre et l'invention de la modernité occidentale. Paris, França: Belin.

Burke, P. (Org.). (1992). A escrita da história: Novas perspectivas. São Paulo, SP: Editora Unesp.

Campanella, B., \& Barros, C. (Eds.). (2016). Etnografia e consumo midiático: Novas tendências e desafios metodológicos. Rio de Janeiro, RJ: E-papers.

Chartier, R. (2002). A história cultural: Entre práticas e representações. Lisboa, Portugal: Difel.

Deleuze, G., \& Guattari, F. (1976). O anti-Édipo: Capitalismo e esquizofrenia. Rio de Janeiro, RJ: Imago.

Descola, P. (2006). As lanças do crepúsculo: Relações jivaro na Alta Amazônia. São Paulo, SP: Cosac Naify.

Geertz, C. (1983). Nova luz sobre a antropologia. Rio de Janeiro, RJ: Jorge Zahar.

Gonçalves, M. S.; Clair, E. T. S. (2014). Meios na história, história nos meios: paradigmas para a reflexão sobre comunicação e cultura. Tríade: Comunicação, Cultura e Mídia, 2(4), 157-172.

Innis, H. A. (2007). Empire and communications. Lanham, MD: Rowman \& Littlefield. Johns, A. (1998). The nature of the book: Print and knowledge in the making. Chicago, IL: The University of Chicago Press.

Le Roy Ladurie, E. (1997). Montaillou, povoado occitânico, 1294-1324. São Paulo, SP: Companhia das Letras.

Lévi-Strauss, C. (2010). La pensée sauvage. Paris, França: Pocket-Plon.

McLuhan, M. (2005). Os meios de comunicação como extensões do homem. São Paulo, SP: Cultrix.

Mcluhan, M., \& Mcluhan, E. (2007). Laws of media: The new science. Toronto, Canadá: University of Toronto Press.

Peirano, M. (1995). A favor da etnografia. Rio de Janeiro, RJ: Relume-Dumará.

Revel, J. (Ed.). (1998). Jogos de escalas: A experiência da microanálise. Rio de Janeiro, RJ: Editora FGV.

Schmandt-Besserat, D. (2006). How writing came about. Austin, TX: University of Texas Press.

Simondon, G. (2007). L'individuation psychique et collective. Paris, França: Aubier. Zola, E. (1979). Germinal. São Paulo, SP: Abril Cultural. 